\title{
GABA Release from Proopiomelanocortin Neurons
}

\author{
Shane T. Hentges, ${ }^{1}$ Mitsuru Nishiyama, ${ }^{2}$ Linda S. Overstreet, ${ }^{1}$ Mary Stenzel-Poore, ${ }^{2}$ John T. Williams, ${ }^{1}$ and \\ Malcolm J. Low ${ }^{1,3,4}$ \\ ${ }^{1}$ Vollum Institute, ${ }^{2}$ Department of Molecular Microbiology and Immunology, ${ }^{3}$ Department of Behavioral Neuroscience, and ${ }^{4}$ Center for the Study of Weight \\ Regulation and Associated Disorders, Oregon Health and Science University, Portland, Oregon 97239
}

Neural networks controlling food intake and energy homeostasis clearly involve proopiomelanocortin (POMC) neurons and their peptide transmitters. $\alpha$-melanocyte-stimulating hormone from arcuate POMC neurons potently reduces food intake, whereas arcuate neuropeptide Y (NPY) neurons act in opposition to stimulate food intake. In addition to orexigenic peptides, NPY neurons also release the inhibitory neurotransmitter GABA, which can act in a local circuit to inhibit POMC neuron activity. Whether or not reciprocal inhibition could occur has not yet been determined, because the presence of a rapid neurotransmitter in POMC neurons has not been demonstrated previously. Here, we used primary cultures of fluorescently labeled POMC neurons that had formed recurrent synapses (autapses) to detect the release of neurotransmitter. When an action potential was evoked in the axon of a POMC neuron with autapses, a short-latency synaptic current was recorded in the same cell. The autaptic current was abolished by $\mathrm{GABA}_{\mathrm{A}}$ receptor antagonists and substantially inhibited by opioids. Double-label in situ RNA hybridization for POMC and glutamic acid decarboxylase, the GABA synthetic enzyme, revealed colocalization of mRNAs in approximately one-third of POMC neurons in vivo. Our results suggest that these neurons can exert rapid inhibitory effects via the release of GABA, in addition to the more sustained actions provided by POMC peptides. However, this rapid inhibition may not play a major role within local hypothalamic circuits, but rather is likely to be important in more distant projection areas as indicated by the colocalization of vesicular GABA transporter immunoreactivity predominately in extrahypothalamic POMC terminals.

Key words: arcuate nucleus; opioids; neuron culture; hypothalamus; autapse; transgenic mouse; green fluorescent protein

\section{Introduction}

Neurons in the arcuate nucleus that express the pomc gene and its peptide products play a critical role in maintaining energy homeostasis. Disruptions in pomc expression or in the signaling of POMC peptides lead to obesity in mice and humans (for review, see Spiegelman and Flier, 2001). The ability of POMC neurons to regulate aspects of energy homeostasis is largely attributable to the expression of the melanocortin peptides $\alpha$-melanocytestimulating hormone $(\alpha-\mathrm{MSH})$ and ACTH and to the opioid $\beta$-endorphin ( $\beta$-end), all products of the same POMC prohormone. $\alpha$-MSH has a potent inhibitory effect on food intake, whereas $\beta$-end has been implicated in mediating the rewarding aspects of food intake. It is not yet clear how POMC neurons coordinate their various and sometimes opposing peptide actions. However, the projections of these neurons are widely distributed both in and outside the hypothalamus and are heavily interconnected within the arcuate nucleus (Eskay et al., 1979; Chen and Pelletier, 1983; Kiss and Williams, 1983).

Additionally, POMC neurons receive input from other arcu-

Received Aug. 26, 2003; revised Dec. 9, 2003; accepted Dec. 15, 2003.

This work was supported by National Institutes of Health Grants DK62219, DK55819, DA08163, and DK07674. We thank J. Smart and M. Rubinstein for their contributions to the generation of POMC-EGFP transgenic mice and R. Simerly for invaluable advice concerning in situ hybridization and photomicroscopy.

Correspondence should be addressed to Dr. Shane T. Hentges, Vollum Institute L-474, Oregon Health and Science University, 3181 Southwest Sam Jackson Park Road, Portland, OR 97239. E-mail: hentgess@ohsu.edu. D01:10.1523/JNEUROSCI.3952-03.2004

Copyright $\odot 2004$ Society for Neuroscience $\quad$ 0270-6474/04/241578-06\$15.00/0 ate neurons that also regulate energy homeostasis. The interaction between POMC and neuropeptide Y (NPY) neurons and their peptides has been studied extensively. In general, NPY and POMC neurons exert opposing actions on energy balance with NPY increasing food intake. Recently, it has been demonstrated that a subpopulation of NPY neuron terminals contains GABA and synapses on POMC neurons (Cowley et al., 2001), suggesting that activation of NPY neurons may inhibit POMC neuron activity through the release of this inhibitory transmitter. Given the functional opposition of POMC and NPY neurons, it is possible that reciprocal inhibition could also occur. However, the presence of a rapid neurotransmitter in POMC neurons has not been described previously.

There are only $\sim 3000$ POMC neurons in the mouse arcuate nucleus, precluding specific biochemical studies on these neurons. Previous attempts to detect neurotransmitter in POMC neurons using immunocytochemical approaches (Ovesjo et al., 2001) have been unsuccessful, presumably because of insufficient sensitivity of the assays and the relatively small number of POMC neurons. In the present study, we used a more sensitive electrophysiological approach to detect fast transmitter release from POMC neurons. Using fluorescently labeled POMC neurons that formed recurrent synapses (autapses) in culture, a subpopulation of these neurons was found to release GABA. Because POMC neurons release and are sensitive to opioids, we also studied the ability of opioids to modulate GABA release. In addition, the GABAergic nature of POMC neurons in vivo was determined by 
colocalization studies using in situ RNA hybridization for $\mathrm{gad}$ mRNA and immunofluorescence for the vesicular GABA transporter (vGAT).

\section{Materials and Methods}

Animals and tissue preparation. Eight-week-old wild-type C57BL/6 J mice were purchased from The Jackson Laboratory (Bar Harbor, ME). POMC-enhanced green fluorescent protein (EGFP) mice were produced in our laboratory as described previously (Cowley et al., 2001), and the transgene has been maintained on the C57BL/6J genetic background. All mice were housed under controlled temperatures $\left(22-24^{\circ} \mathrm{C}\right)$ and a constant $12 \mathrm{hr}$ light/dark schedule and given standard chow and tap water ad libitum. All experimental procedures met United States Public Health Service guidelines with the approval of the Institutional Animal Care and Use Committee of the Oregon Health and Science University.

Primary hypothalamic cultures. Hypothalami were collected from young adult POMC-EGFP mice (8-12 weeks of age) into ice-cold dissociation media (in mM): $80 \mathrm{Na}_{2} \mathrm{SO}_{4}, 30 \mathrm{~K}_{2} \mathrm{SO}_{4}, 12 \mathrm{MgCl}_{2}, 0.25 \mathrm{CaCl}_{2}, 4$ HEPES, 20 glucose, and $0.001 \%$ phenol red, $\mathrm{pH}$ 7.4. Tissue was minced, and cells were mechanically dissociated after exposure to papain (20 $\mathrm{U} / \mathrm{ml}$; Worthington, Lakewood, NJ). Cells were seeded on poly-L-lysinecoated glass coverslips in Neurobasal A medium (Invitrogen, Grand Island, NY) supplemented with $1 \times$ B27 (Invitrogen), 0.4 mM L-glutamine, and $1 \%$ fetal calf serum. A $25 \mu \mathrm{M}$ concentration of glutamic acid was added for the initial plating. The media were replenished every $3-5 \mathrm{~d}$, and whole-cell recordings were made between days 7 and 10 in culture. Plating the hypothalamic cells at low density $(\sim 30,000$ cells per well of a 24 well plate) was sufficient to encourage the formation of autapses.

Immunodetection of endogenous POMC peptides in cultured neurons. To determine whether cultured POMC neurons continued to express endogenous peptides after a prolonged time in culture, immunofluorescence histochemistry was performed in POMC-EGFP neurons that had been cultured for 4 weeks. The cells were rinsed with PBS and fixed with $4 \%$ paraformaldehyde and $4 \%$ sucrose in PBS. Nonspecific binding was blocked with 5\% normal goat serum in PBS. The cells were then exposed to either rabbit anti- $\beta$-endorphin antibody $(1: 8000)$ or rabbit antiACTH (1:8000) (gift from A. F. Parlow, National Hormone and Peptide Program, Torrance, CA) overnight at $4^{\circ} \mathrm{C}$. The cells were rinsed in PBS, and biotinylated goat anti-rabbit secondary antibody (1:500; Vector Laboratories, Burlingame, CA) was added for $2 \mathrm{hr}$ at room temperature. $\beta$-endorphin or ACTH immunoreactivity was detected using a streptavidin-Cy3-conjugated fluorophore (1:500; Jackson ImmunoResearch, West Grove, PA). Nuclei were labeled with 4',6'-diamidino-2phenylindole (DAPI) in the mounting medium.

Whole-cell recordings. Cultures were perfused with Krebs' solutionbicarbonate buffer containing the following (in $\mathrm{mm}$ ): $126 \mathrm{NaCl}, 2.5 \mathrm{KCl}$, $1.2 \mathrm{NaH}_{2} \mathrm{PO}_{4}, 1.2 \mathrm{MgCl}_{2}, 2.4 \mathrm{CaCl}_{2}, 11$ glucose, and $21.4 \mathrm{NaHCO}_{3}$ saturated with $95 \% \mathrm{O}_{2}$ and $5 \% \mathrm{CO}_{2}$. Cells expressing EGFP were readily detected by excitation at $450-485 \mathrm{~nm}$ and viewed with a 520 filter. Whole-cell voltage clamp recordings were made with an internal solution containing the following (in $\mathrm{mM}$ ): $115 \mathrm{KCl}, 20 \mathrm{NaCl}, 1.5 \mathrm{MgCl}_{2}, 0.1$ EGTA, 10 phosphocreatine, $2 \mathrm{Mg}$-ATP, and $0.5 \mathrm{GTP}$, buffered with 5 HEPES, $\mathrm{pH}$ 7.3. Patch pipettes had a tip resistance of $1-2 \mathrm{M} \Omega$ when filled with internal solution, and only cells with an input resistance of $>1 \mathrm{G} \Omega$ were used. Drugs were applied by superfusion. Whole-cell recordings were made with an Axopatch 200B amplifier (Axon Instruments, Foster City, CA). Recordings and analyses were obtained using AxoGraph software (Axon Instruments).

Double-label in situ hybridization. Mice were deeply anesthetized with isoflurane and perfused transcardially with ice-cold $4 \%$ paraformaldehyde in $0.1 \mathrm{~m}$ borate buffer, $\mathrm{pH} 9.5$, after which the brains were quickly removed and postfixed overnight at $4^{\circ} \mathrm{C}$ in the same fixative containing $20 \%$ sucrose. Twenty-micrometer-thick cryosections containing the arcuate nucleus were collected in chilled $0.02 \mathrm{M}$ potassium PBS that contained $0.25 \%$ paraformaldehyde, $\mathrm{pH} 7.4$, and were mounted onto gelatin-subbed, poly-L-lysine-coated slides. After a $30 \mathrm{~min}$ proteinase $\mathrm{K}$ digestion $\left(10 \mathrm{mg} / \mathrm{ml}\right.$ at $\left.37^{\circ} \mathrm{C}\right)$ and acetylation $(0.0025 \%$ at room temperature), the sections were dehydrated in ascending alcohols and dried under vacuum for at least $2 \mathrm{hr}$.
Double in situ hybridization was performed essentially as described previously by Simerly et al. (1996), who kindly provided us with their protocol. The probe for gad mRNA corresponded to $500 \mathrm{bp}$ of the $3^{\prime}$ untranslated region of gad67 and was synthesized using SP6 polymerase to transcribe ${ }^{33} \mathrm{P}$-labeled antisense cRNA (the rat-gad-containing plasmid, \#14, was originally provided by A. J. Tobin, Hannover, Germany). In vitro transcription of the mouse pomc probe, which corresponds to 450 bp of exon 3 and $150 \mathrm{bp}$ of the pomc gene $3^{\prime}$ flanking region, was performed in the presence of digoxigenin-labeled UTP. Both probes were simultaneously hybridized with tissue sections for $20 \mathrm{hr}$ at $68^{\circ} \mathrm{C}$. Localization of digoxigenin-labeled POMC hybrids was performed by incubating the sections in a 1:1000 dilution of the anti-digoxigenin alkaline phosphatase conjugate for $5 \mathrm{hr}$ at room temperature followed by treatment with $3.38 \mathrm{mg} / \mathrm{ml}$ nitroblue tetrazolium, $1.75 \mathrm{mg} / \mathrm{ml}$ 5-bromo-4chloro-3-indolyl phosphate, and $3 \mathrm{mg} / \mathrm{ml}$ levamisole. The sections were then rapidly dehydrated in ethanol (containing SSC and DTT), dried under vacuum for $30 \mathrm{~min}$, and then processed for autoradiography to detect ${ }^{33} \mathrm{P}$-labeled gad mRNA hybrids. The slides were dipped in Ilford $\mathrm{K} 5$ emulsion. The dipped autoradiograms were developed $28 \mathrm{~d}$ later with Kodak (Rochester, NY) D-19 developer, and the sections were counterstained with thionin through the emulsion. The slides were washed, dehydrated in ethanol, dried under vacuum for $30 \mathrm{~min}$, and coverslipped with DPX. Photomicrographs were obtained using a Leitz (Wetzlar, Germany) upright research microscope with a $50 \times$ oil-immersion lens. To visualize both signals simultaneously, the silver grains were illuminated with epipolarization optics and simultaneously visualized against the dark digoxigenin-labeled soma of POMC neurons in bright field.

Immunodetection of $v G A T$ and GABA. Four POMC-EGFP-positive mice were deeply anesthetized and transcardially perfused with $0.9 \%$ normal saline and then perfused with $4 \%$ phosphate-buffered ice-cold paraformaldehyde. Coronal brain sections (50 $\mu \mathrm{m}$ thick) were prepared on a vibratome and stored in antifreeze solution (30\% ethylene glycol, $20 \%$ glycerol, and $50 \% 0.05 \mathrm{M}$ phosphate buffer) at $-20^{\circ} \mathrm{C}$ until use. Immunodetection of vGAT or GABA was performed using methods similar to those described previously (Cueva et al., 2002). Briefly, sections were washed three times for $10 \mathrm{~min}$ in PBS containing $0.3 \%$ Triton X-100 (PBST) and then placed in PBST with 5\% normal goat serum for $1 \mathrm{hr}$. Rabbit anti-rat vGAT ( $5 \mu \mathrm{g} / \mathrm{ml}$; Chemicon International, Temecula, CA) or rabbit anti-GABA (1:20,000; Sigma, St. Louis, MO) was added to the blocking buffer, and sections were incubated overnight at $4^{\circ} \mathrm{C}$. For some sections, the primary antibody was omitted as a control. Tissue was washed three times for $20 \mathrm{~min}$ in PBST, and the vGAT or GABA immunoreactivity was detected using a Cy3-conjugated goat anti-rabbit secondary antibody (1:400; Jackson ImmunoResearch). Slices were washed in PBS and mounted with ProLong Antifade (Molecular Probes, Eugene, OR). Labeled cells were visualized using confocal microscopy with a $60 \times$ oil-immersion lens.

\section{Results}

\section{Identified POMC neurons in culture}

POMC-EGFP neurons were readily identified in primary hypothalamic cultures by the excitation of EGFP at $450-480 \mathrm{~nm}$ (Fig. $1 A)$. The cultured neurons remained healthy and continuously expressed EGFP for several weeks. POMC-EGFP neurons maintained in vitro also continued to express endogenous POMC peptides. Immunofluorescence was used to detect the presence of $\beta$-endorphin (Fig. 1C) and ACTH (data not shown) in POMCEGFP neurons after 4 weeks in culture. All of the EGFPexpressing neurons examined ( $\sim 300$ cells from three different cultures) displayed colocalization of EGFP and $\beta$-endorphin (Fig. $1 E$ ) or EGFP and ACTH, similar to previous results obtained in hypothalamic sections from POMC-EGFP transgenic mice (Cowley et al., 2001).

\section{Release of GABA from POMC neurons}

The release of transmitter from POMC-EGFP neurons was detected using cultured neurons that had formed recurrent syn- 

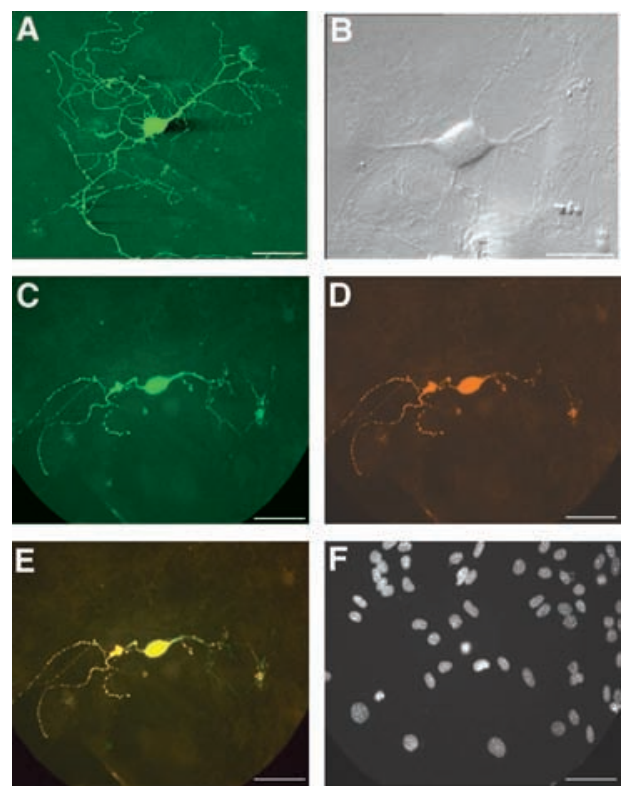

Figure 1. Primary cultures of POMC-EGFP neurons. $A$, POMC neurons were maintained in low-density primary cultures for several weeks, and extensive EGFP-filled processes were easily visualized around each POMC cell soma. B, A higher-power, bright-field image of a POMC-EGFP neuron typical of those used for electrophysiological recordings. $C-F$, Hypothalamic neurons were grown in culture for 4 weeks and then fixed and processed for immunofluorescence to detect endogenous $\beta$-endorphin. Colocalization of EGFP ( $C$ and $\beta$-endorphin ( $D)$ was evident. The merged image of $C$ and $D$ is shown in $E$. F, The nuclei were labeled with DAPI. Scale bars, $20 \mu \mathrm{m}$.

apses (autapses) (Fig. 2A). Whole-cell voltage-clamp recordings were made in neurons held at $-60 \mathrm{mV}$ and depolarized to $0 \mathrm{mV}$ for $2 \mathrm{msec}$ to evoke an action potential. The resulting autaptic current was blocked by the $\mathrm{GABA}_{\mathrm{A}}$ receptor antagonist bicuculline $(10 \mu \mathrm{M})$ (Fig. $2 B, C)$ by $93 \pm 5.7 \%(n=6)$. In a separate experiment, picrotoxin $(100 \mu \mathrm{M})$ also blocked the evoked autaptic current $(n=5$; data not shown) and the autaptic current was abolished by tetrodotoxin $(1 \mu \mathrm{M})$.

\section{Opioid actions in cultured POMC neurons}

To determine whether cultured POMC neurons maintained the basic physiological characteristics in culture as described previously for these neurons in slice recordings, we tested the actions of opioids. As expected, the opioid $[\mathrm{Met}]^{5}$-enkephalin (ME; 10 $\mu \mathrm{M}$ ) induced an outward current in the POMC neurons (Fig. 2D) consistent with previous reports (Kelly et al., 1990; Cowley et al., 2001; Ibrahim et al., 2003). The current-voltage plot indicates that $\mathrm{ME}$ activated an inwardly rectifying channel with a reversal potential at the potassium equilibrium potential (Fig. $2 E$ ). Inhibition of transmitter release is a common action of opioids (for review, see Williams et al., 2001). In cultured POMC neurons, $\mathrm{ME}(10 \mu \mathrm{M})$ inhibited the $\mathrm{GABA}_{\mathrm{A}}$-mediated IPSCs from POMC neurons by $64 \pm 6 \%(n=12)$ (Fig. $2 F)$.

\section{In situ detection of GAD}

Double-label in situ hybridization was performed to determine whether POMC neurons in vivo could be GABAergic. The presence of mRNA transcripts encoding GAD, the enzyme responsible for the production of GABA, was detected using a ${ }^{33} \mathrm{P}$-labeled riboprobe. Extensive gad mRNA was detected in specific areas throughout the brain, including an intense gad signal in the arcuate nucleus (Fig. 3A). Pomc mRNA was detected using a digoxigenin-labeled riboprobe that hybridized specifically to neurons in the arcuate nucleus (Fig. 3B). A substantial propor- tion of arcuate neurons expressed both gad and pomc mRNA (35 $\pm 3 \%$ of POMC neurons express gad, three sections were counted from each of the five mice) (Fig. 3C). Many cells expressed only gad, as expected from the reports of various GABAergic cell types in the arcuate nucleus. Some POMC neurons did not show clear gad mRNA, indicating that there may be heterogeneity of POMC neurons.

\section{Expression of vGAT in POMC terminals}

Inhibitory terminals contain vGAT (McIntire et al., 1997; Chaudhry et al., 1998; Jin et al., 2003). Therefore, to localize GABAergic POMC terminals, the coexistence of vGAT and EGFP was examined in tissue sections from POMC-EGFP transgenic mice. Immunoreactive vGAT was present throughout the arcuate, as were POMC neuronal cell bodies and terminal-like varicosities (Fig. 4A). However, there was very little overlap between vGAT and EGFP expression (Fig. $4 A$, right two panels) in the arcuate nucleus. POMC fibers and putative terminals were observed throughout various other hypothalamic nuclei, also with no appreciable vGAT colocalization. An area of the dorsomedial nucleus is shown in Figure $4 B$. There was little or no overlap between EGFP and vGAT in the lateral hypothalamus or in the paraventricular nucleus (data not shown).

In several extrahypothalamic sites examined, vGAT was colocalized with EGFP. In the central nucleus of the amygdala, there was strong vGAT immunoreactivity in EGFP-containing terminal-like varicosities (Fig. 4C). Colocalization of vGAT and EGFP was also consistently observed in the thalamic nuclei and the midbrain (data not shown). The representative images shown in Figure 4 were all taken from a single tissue section to ensure uniformity in antibody treatment and signal detection. Three sections containing the arcuate nucleus were examined for each of the four animals. All sections displayed a similar pattern of vGAT and EGFP expression as described above. There was no clear Cy3 signal in sections in which the primary antibody had been omitted.

\section{Expression of GABA in POMC terminals}

To confirm the GABAergic phenotype of POMC neurons in vivo that was implied by the detection of vGAT, immunodetection of GABA was also performed. The pattern of GABA immunoreactivity in relation to EGFP was consistent with that found for vGAT, although overall there was more immunoreactive GABA detected than vGAT. In the arcuate nucleus, POMC-EGFP soma, fibers, and putative terminals were apparent as well as immunoreactive GABA; however, there was little overlap (Fig. 5A). POMC fibers and putative terminals in the dorsomedial nucleus of the hypothalamus and various other hypothalamic nuclei, including the lateral hypothalamus and the paraventricular nucleus, also displayed no appreciable GABA colocalization (data not shown). In the ventromedial thalamus (Fig. 5B) and the central nucleus of the amygdala (Fig. 5C), GABA was extensively colocalized with EGFP. The representative images shown in Figure 5 were all taken from a single tissue section to ensure uniformity in antibody treatment and signal detection. Three sections containing the arcuate nucleus were examined for each of the four animals. All sections displayed a similar pattern of GABA and EGFP expression, as described above. There was no clear Cy3 signal in sections in which the primary antibody had been omitted. Immunoreactive GABA was also detected in cultured POMC neurons (data not shown), as expected from the electrophysiological data. 
A

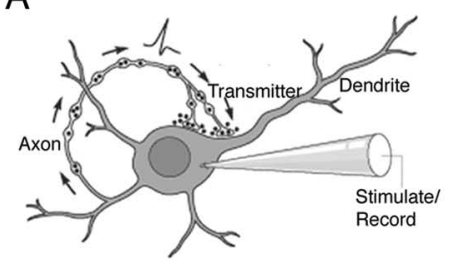

B

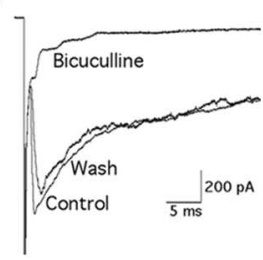

D

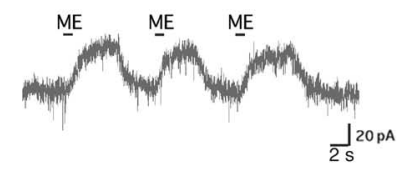

E

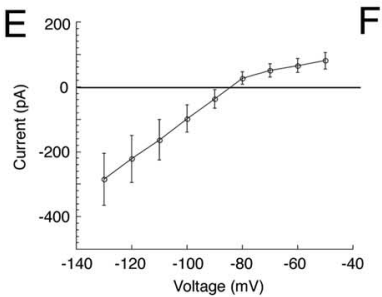

C
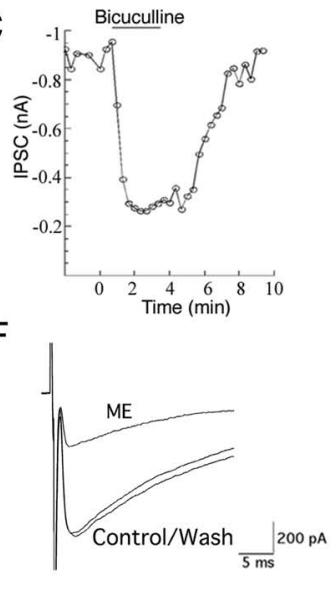

Figure 2. POMC neurons release GABA and respond to opioids. A, Transmitter release was detected from POMC neurons that had formed autosynapses in culture. An action potential was evoked, and the resulting autaptic current was recorded via the same electrode. B, C, In POMC neurons, the evoked autaptic current was blocked by bath perfusion of bicuculline (10 $\mu \mathrm{M})$. Autaptic currents were evoked every $20 \mathrm{sec}$. The peak amplitude from each trace during an experiment is plotted in C.D, When held at -60 $\mathrm{mV}$, the cultured neurons responded to $\mathrm{ME}(10 \mu \mathrm{M})$ with an outward current. $E, \mathrm{~A}$ current-voltage plot for $\mathrm{ME}(10 \mu \mathrm{M})$ was constructed from responses in four cells (error bars indicate \pm SEM). F, ME (10 $\mu \mathrm{M})$ inhibited the evoked autaptic current.
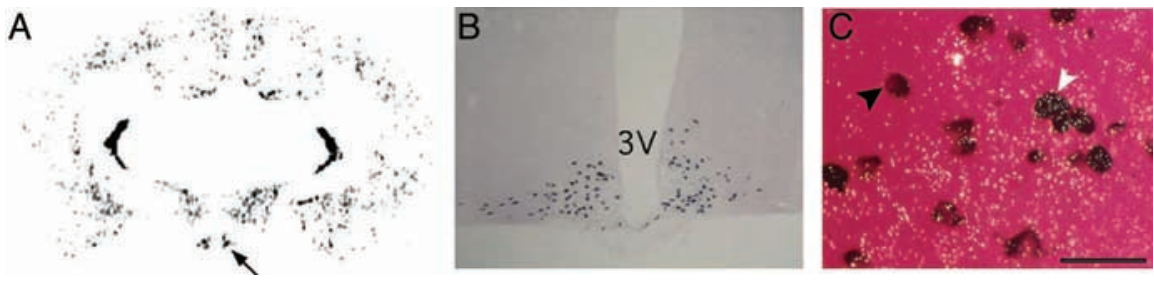

Figure 3. Detection of GAD in POMC neurons. Double-label in situ hybridization for gad $(A)$ and pomc $(B)$ mRNAs revealed that POMC neurons in vivo express GAD ( $C$, further indicating the GABAergic nature of these neurons. 3V, Third ventricle. C, Using epi-illumination to visualize the silver grains of the gad probe, white grains can be seen over the purple digoxigenin-labeled POMC neurons (white arrowhead). Some POMC neurons do not contain significant gad mRNA (black arrowhead), and many non-POMC neurons in the arcuate nucleus express gad. Scale bar, $20 \mu \mathrm{m}$.

\section{Discussion}

Our results demonstrate that POMC neurons can synthesize and release the classical neurotransmitter GABA. The presence of this inhibitory neurotransmitter in POMC neurons indicates that these neurons can exert rapid inhibitory actions, in addition to the more prolonged actions attributed to POMC peptide release. The marker of GABAergic terminals, vGAT, was colocalized with pomc promoter-driven EGFP predominately in extrahypothalamic regions but not in the hypothalamic nuclei that are densely innervated by POMC axons. This heterogeneity of POMC terminals at discrete target sites could account for some of the functional diversity of these neurons and their peptides in the regulation of energy homeostasis.

\section{GABA release from POMC neurons}

Autapses in cultured POMC neurons provided a sensitive assay to detect and characterize fast synaptic transmitters. The autaptic current was blocked by both $\mathrm{GABA}_{\mathrm{A}}$ antagonists and tetrodotoxin, indicating an action potential-dependent release of GABA. Not all cultured POMC neurons displayed autaptic currents; however, it was impossible to determine whether the lack of an autaptic current was attributable to the absence of a rapid transmitter or rather to the absence of recurrent synapses in those cells.

Although the use of autapses is a highly sensitive method for detecting transmitter release, there was some concern that cul- tured neurons may have a different phenotype than their in vivo counterparts. The cultured POMC-EGFP neurons continued to express $\beta$-endorphin and ACTH and were inhibited by $[\mathrm{Met}]^{5}$-enkephalin, characteristics consistent with previous reports for POMC-EGFP neurons in vivo (Cowley et al., 2001; Ibrahim et al., 2003). In previous reports, it has been demonstrated that under specific conditions, neurons that are generally glutamatergic can release GABA (Bergersen et al., 2003; Ruiz et al., 2003). Perhaps by culturing neurons, such alterations in transmitter release could occur. It seems unlikely that this would happen in the present studies, because the neurons were collected from adult mice naive to any treatment that might encourage such a change in the type of transmitter released. The presence of GABA in POMC neurons in vivo also indicates that the release of GABA does not occur as a result of the culture conditions. Although the release of glutamate was never detected in the autapse studies, it is possible that the culture conditions favor GABAergic POMC neurons and select against other transmitter phenotypes. However, there are numerous reports of autaptic glutamate release from cultured neurons illustrating that there is no general selection against cells releasing glutamate from autapses.

To determine whether POMC neurons in situ have the potential to release GABA, we performed dual-label mRNA colocalization studies that revealed the presence of gad mRNA in $~ 35 \%$ of POMC neurons. GAD is the synthetic enzyme necessary for GABA production, and its presence is indicative of GABAergic cells. Because the arcuate nucleus is a highly GABAergic structure, the gad signal was strong over neurons throughout the nucleus. To reduce the chance of false-positive identification attributable to silver grains from neighboring or overlapping cells, the minimum criteria to count a cell as gad-positive was set fairly high at 20 grains per cell. Therefore it is possible that we may be underestimating the fraction of POMC cells that are GABAergic. The percentage of POMC cells expressing gad in the current study is very similar to that reported previously for the neighboring NPY neurons (Horvath et al., 1997), indicating that heterogeneity of transmitter expression may be a characteristic of peptide neurons in this nucleus.

\section{Heterogeneity of POMC-EGFP projections}

In regard to energy homeostasis, NPY/agouti gene-related protein (AGRP) neurons are often considered to functionally oppose POMC neurons via parallel projections to relevant brain nuclei. In general, NPY increases food intake and decreases metabolism, whereas $\alpha$-MSH from POMC neurons decreases food intake and increases metabolism. In addition, AGRP from NPY neurons acts as a functional antagonist of $\alpha$-MSH at melanocortin receptors (MacNeil et al., 2002). Recent reports have demonstrated that 
vGAT
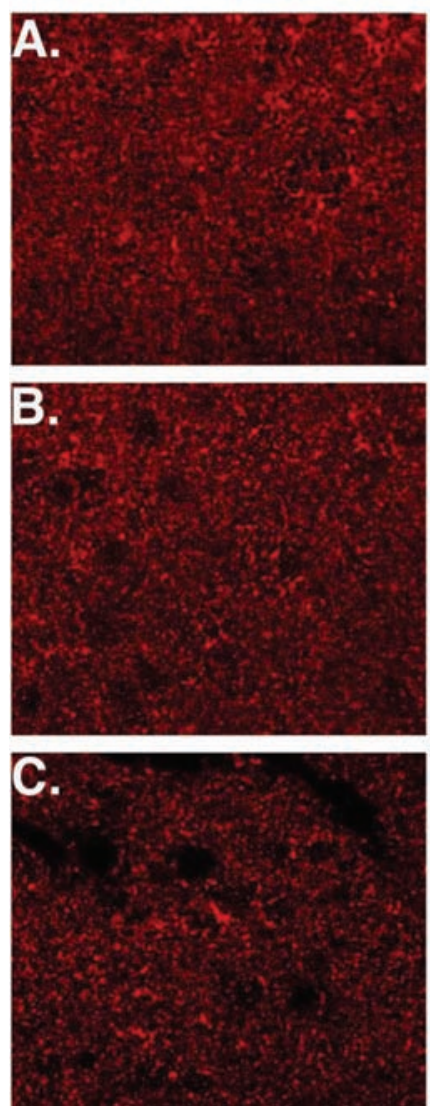

EGFP
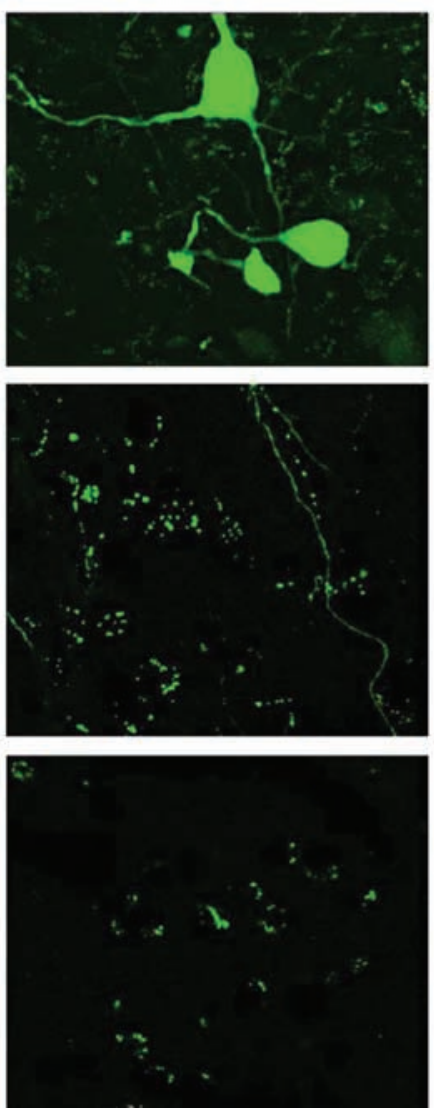

Merge
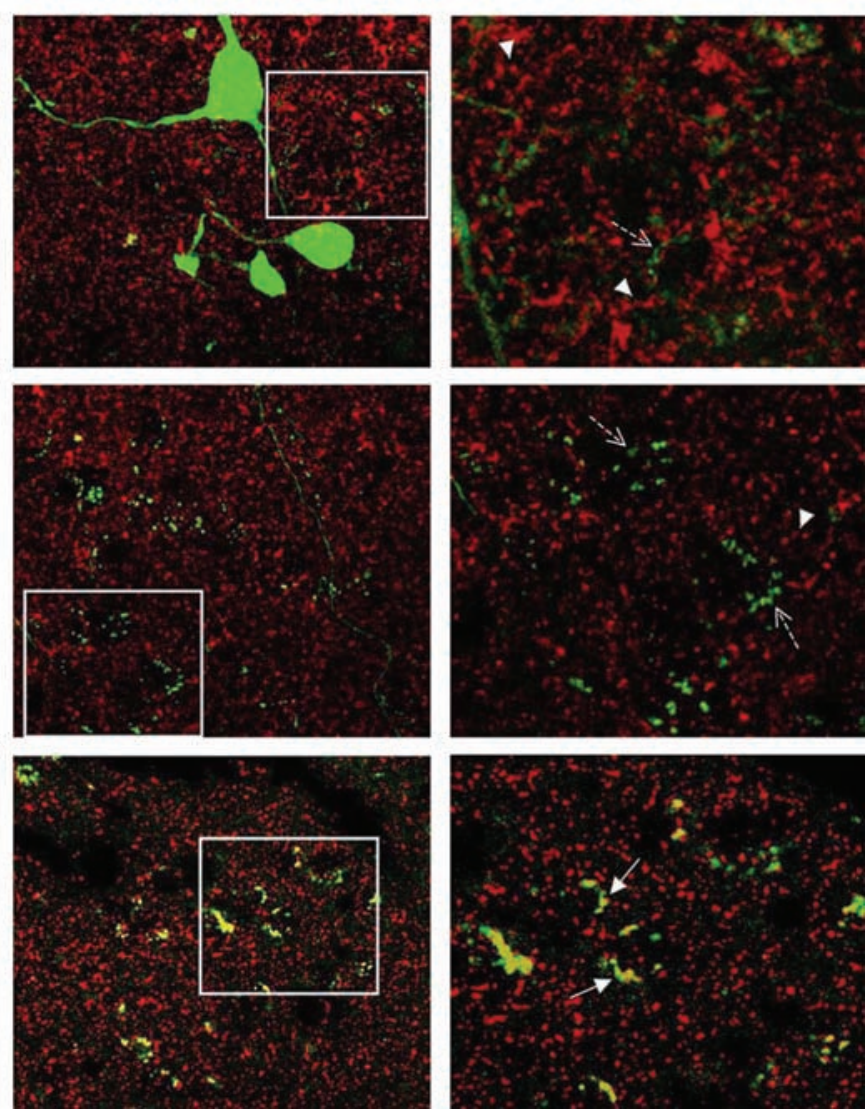
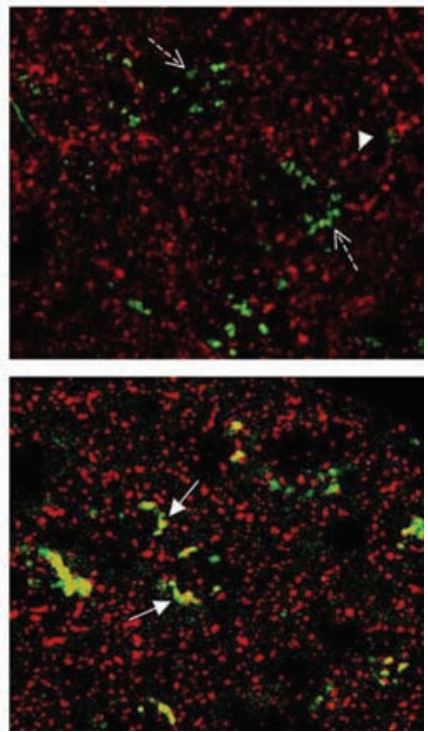

Figure 4. Localization of vGAT-containing POMC terminals. vGAT immunoreactivity was used to detect inhibitory terminals in the arcuate nucleus of the hypothalamus ( $A$ ), the dorsomedial nucleus of the hypothalamus $(B)$, and the central nucleus of the amygdala $(C)$. The $60 \times$ oil-immersion confocal images were obtained from a single coronal section. $\mathrm{vGAT}$ immunoreactivity is shown in red (white arrowheads), and EGFP-positive cells and terminals are green (dashed arrows indicate EGFP-positive terminal-like varicosities). In the amygdala, there was a high degree of colocalization between EGFP and vGAT, as indicated by the yellow signal in the merged image ( $C$, white arrows). The images in the far right column are $3 \times$ enlargements of the areas within the white boxes.

NPY neurons can also inhibit POMC neuron activity by releasing GABA directly onto POMC neurons (Horvath et al., 1997; Cowley et al., 2001). Therefore, we hypothesized that POMC neurons could reciprocally inhibit NPY neurons via the release of GABA. The finding that cultured POMC neurons can release GABA supported this possibility; however, essentially no POMC-EGFP and vGAT or GABA colocalization was observed in the arcuate nucleus. Although it remains possible that POMC neurons could inhibit NPY neurons via the release of their peptide transmitters, inhibition by POMC neuron-derived GABA appears unlikely.

POMC-EGFP varicosities were localized around many cells in the arcuate nucleus (Fig. $4 A$ ), which is consistent with previous reports of POMC terminals in this nucleus (Chen and Pelletier, 1983; Kiss and Williams, 1983). In the transgenic model used in the present studies, soluble EGFP is expressed specifically in POMC neurons and freely diffuses into all processes and terminals in addition to the cell bodies. The pattern of vGAT immunofluorescence that we observed was consistent with previous reports, which demonstrated that vGAT is specifically expressed in inhibitory terminals (Chaudhry et al., 1998). Therefore, we considered structures that contained EGFP and demonstrated vGAT immunoreactivity to be POMC/GABA terminals. This was additionally confirmed by the detection of GABA in POMC terminals.
The presence of gad mRNA, vGAT, and GABA strongly suggests that POMC neurons can make and release GABA from a subset of terminals. Our observation that neither vGAT nor GABA is colocalized in POMC terminals within the arcuate is consistent with a previous report that examined GABA and POMC colocalization by dual-antibody immunofluorescence in this nucleus (Ovesjo et al., 2001). However, POMC-EGFP terminals containing vGAT or GABA were abundant in extrahypothalamic target sites. The expression of GABA in specific sites may suggest a more general heterogeneity of POMC terminals. It is known that $\alpha$-MSH and $\beta$-end are coproduced in POMC neurons. However, it remains unclear as to whether they are necessarily released under the same conditions, from the same vesicles, or even from the same terminals. Many homeostatic effects of $\alpha$-MSH occur via actions within hypothalamic nuclei, whereas $\beta$-end has been more heavily implicated in regulating the rewarding aspects of food intake, which primarily involve extrahypothalamic regions, including the extended amygdala complex. Therefore, although the present studies do not support the hypothesis that POMC neurons inhibit arcuate NPY neurons via the release of GABA, our data suggest the interesting possibility that GABA release could occur in a subset of POMC terminals with a specific peptide phenotype. 

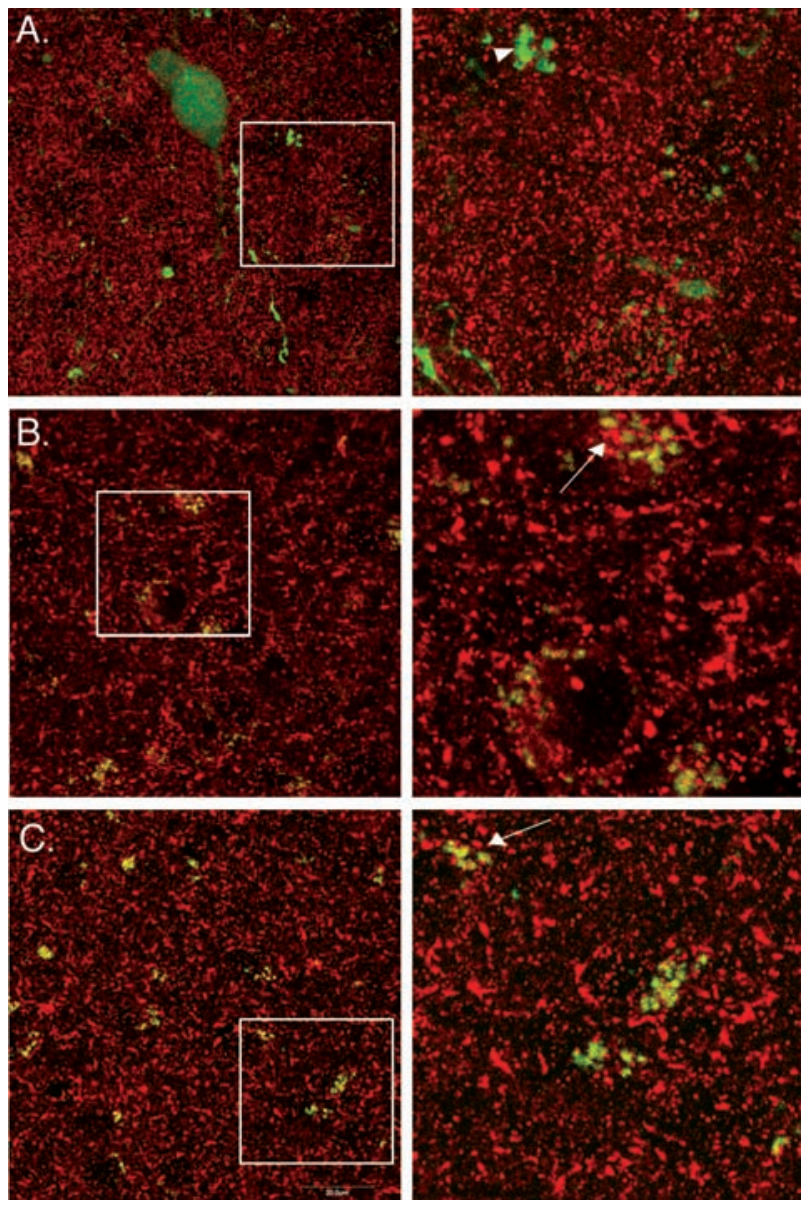

Figure 5. Localization of GABA in POMC terminals. GABA immunoreactivity was used to detect inhibitory terminals in the arcuate nucleus of the hypothalamus $(A)$, the ventromedial thalamus $(B)$, and the central nucleus of the amygdala $(C)$. The $60 \times$ oil-immersion confocal images were obtained from a single coronal section. The images in the right column are $3 \times$ enlargements of the areas within the white boxes. $B, C$, In the ventromedial thalamus and the amygdala, there was a high degree of colocalization between EGFP (green) and GABA (red) as indicated by the yellow signal. The arrowhead in $A$ indicates an area with POMC-EGFP terminallike varicosities. The arrows in $B$ and $C$ indicate areas positive for both EGFP and GABA.

\section{References}

Bergersen L, Ruiz A, Bjaalie JG, Kullmann DM, Gundersen V (2003) GABA and GABAA receptors at hippocampal mossy fibre synapses. Eur J Neurosci 18:931-941.

Chaudhry FA, Reimer RJ, Bellocchio EE, Danbolt NC, Osen KK, Edwards RH, Storm-Mathisen J (1998) The vesicular GABA transporter, VGAT, lo- calizes to synaptic vesicles in sets of glycinergic as well as GABAergic neurons. J Neurosci 18:9733-9750.

Chen YY, Pelletier G (1983) Demonstration of contacts between proopiomelanocortin neurons in the rat hypothalamus. Neurosci Lett 43:271-276

Cowley MA, Smart JL, Rubinstein M, Cerdan MG, Diano S, Horvath TL, Cone RD, Low MJ (2001) Leptin activates anorexigenic POMC neurons through a neural network in the arcuate nucleus. Nature 411:480-484.

Cueva JG, Haverkamp S, Reimer RJ, Edwards R, Wassle H, Brecha NC (2002) Vesicular $\gamma$-aminobutyric acid transporter expression in amacrine and horizontal cells. J Comp Neurol 445:227-237.

Eskay RL, Giraud P, Oliver C, Brown-Stein MJ (1979) Distribution of $\alpha$-melanocyte-stimulating hormone in the rat brain: evidence that $\alpha$-MSH-containing cells in the arcuate region send projections to extrahypothalamic areas. Brain Res 178:55-67.

Horvath TL, Bechmann I, Naftolin F, Kalra SP, Leranth C (1997) Heterogeneity in the neuropeptide Y-containing neurons of the rat arcuate nucleus: GABAergic and non-GABAergic subpopulations. Brain Res 756:283-286.

Ibrahim N, Bosch MA, Smart JL, Qiu J, Rubinstein M, Ronnekleiv OK, Low MJ, Kelly MJ (2003) Hypothalamic proopiomelanocortin neurons are glucose responsive and express K(ATP) channels. Endocrinology 144:1331-1340.

Jin H, Wu H, Osterhaus G, Wei J, Davis K, Sha D, Floor E, Hsu CC, Kopke RD, Wu JY (2003) Demonstration of functional coupling between $\gamma$-aminobutyric acid (GABA) synthesis and vesicular GABA transport into synaptic vesicles. Proc Natl Acad Sci USA 100:4293-4298.

Kelly MJ, Loose MD, Ronnekleiv OK (1990) Opioids hyperpolarize $\beta$-endorphin neurons via $\mu$-receptor activation of a potassium conductance. Neuroendocrinology 52:268-275.

Kiss JZ, Williams TH (1983) ACTH-immunoreactive boutons form synaptic contacts in the hypothalamic arcuate nucleus of rat: evidence for local opiocortin connections. Brain Res 263:142-146.

MacNeil DJ, Howard AD, Guan X, Fong TM, Nargund RP, Bednarek MA, Goulet MT, Weinberg DH, Strack AM, Marsh DJ, Chen HY, Shen CP, Chen AS, Rosenblum CI, MacNeil T, Tota M, MacIntyre ED, Van der Ploeg LH (2002) The role of melanocortins in body weight regulation: opportunities for the treatment of obesity. Eur J Pharmacol 450:93-109.

McIntire SL, Reimer RJ, Schuske K, Edwards RH, Jorgensen EM (1997) Identification and characterization of the vesicular GABA transporter. Nature 389:870-876.

Ovesjo ML, Gamstedt M, Collin M, Meister B (2001) GABAergic nature of hypothalamic leptin target neurones in the ventromedial arcuate nucleus. J Neuroendocrinol 13:505-516.

Ruiz A, Fabian-Fine R, Scott R, Walker MC, Rusakov DA, Kullmann DM (2003) GABAA receptors at hippocampal mossy fibers. Neuron 39:961-973.

Simerly RB, Carr AM, Zee MC, Lorang D (1996) Ovarian steroid regulation of estrogen and progesterone receptor messenger ribonucleic acid in the anteroventral periventricular nucleus of the rat. J Neuroendocrinol 8:45-56.

Spiegelman BM, Flier JS (2001) Obesity and the regulation of energy balance. Cell 104:531-543.

Williams JT, Christie MJ, Manzoni O (2001) Cellular and synaptic adaptations mediating opioid dependence. Physiol Rev 81:299-343. 